\title{
Synthesis and Properties of Alkoxy-substituted Oligothiophene Derivatives
}

\author{
Ichiro Imae*, Yuki Akiyama, and Yutaka Harima \\ Department of Applied Chemistry, Graduate School of Engineering, \\ Hiroshima University, \\ 1-4-1 Kagamiyama, Higashi-Hiroshima, Hiroshima 739-8527, Japan \\ *imae@hiroshima-u.ac.jp
}

\begin{abstract}
Three oligothiophenes containing alkoxy groups were synthesized, and their optical, electrochemical, and electrical properties were investigated. The oligothiophenes were soluble in common organic solvents owing to the presence of flexible alkyl chains in their alkoxy groups. The introduction of alkoxy groups induced a red-shift in the absorption and emission bands and a negative shift in the oxidation potentials observed for the compounds. The extension of the $\pi$-conjugation system enhanced the stability of the oxidized states of the oligothiophenes due to a reduction in the Coulombic repulsion. The electrochemically oxidized dodecathiophene showed excellent electrical conductivity.
\end{abstract}

Keywords: Oligothiophene, Alkoxy group, Well-defined structure, Chalcogen atoms interaction, In-situ conductivity measurements

\section{Introduction}

Since $\pi$-conjugated polymers can reversibly change between their neutral and doped states via a redox reaction, exhibiting semiconductor properties in the neutral state and metallic electrical conductivity in the doped state, they are widely used in organic electronic devices, such as secondary batteries, electroluminescent displays, field-effect transistors, and organic photovoltaic cells [1-6]. In addition, it has been recently reported that they can be applied in organic thermoelectric devices, which have attracted attention as a promising technology for the conversion of large amounts of unused heat [7]. Among them, $\operatorname{poly}(3,4-$ ethylenedioxythiophene) (PEDOT) bearing an electron-donating alkoxy group in its side chain has been extensively studied because of its high electrical conductivity in its doped state [8-14].

Oligothiophenes linked at the $\alpha$-position of the thiophene ring with a controlled degree of polymerization have synthetic reproducibility superior to polythiophenes. Consequently, their optical, electrochemical, and electrical properties can be easily analyzed in relation to the length of their $\pi$-conjugation system. From these results, oligothiophenes have been extensively studied as model compounds to understand the physical properties of polythiophenes [15-19]. More recently, oligothiophenes have been found to exhibit superior properties to polythiophenes due to their welldefined structures, which have been studied as a novel family of functional optical and electronic materials [20-27].

We have recently developed a series of oligothiophenes containing 3,4ethylenedioxythiophene (EDOT) units to improve the physical properties of oligothiophenes and investigated their properties in regard to their chemical structures $[28,29]$. It was found that the introduction of electron-donating ethylenedioxy groups causes a remarkable red-shift in their electronic absorption bands and a negative shift in the oxidation potential when compared with those of oligothiophenes without alkoxy groups containing the same number of thiophene units, which result in excellent charge-transport properties comparable to those of polythiophenes. Furthermore, using these properties, we have successfully developed a dye-sensitizing solar cell and organic photovoltaic cell that can harvest 
sunlight over a wide wavelength range [30-34]. However, although the ethylenedioxy group exhibits electron-donating properties, it is not soluble in common organic solvents because it only contains two methylene groups in its alkyl chain. Thus, the solubility of its oligothiophenes decreases upon increasing the number of thiophene units, which is unfavorable for device fabrication using a wet process.

In this study, we introduce a variety of long chain alkoxy groups instead of the ethylenedioxy group as the side chain in a series of oligothiophenes to introduce both electron-donating properties and solubility, and investigated their optical, electrochemical, and electrical properties.

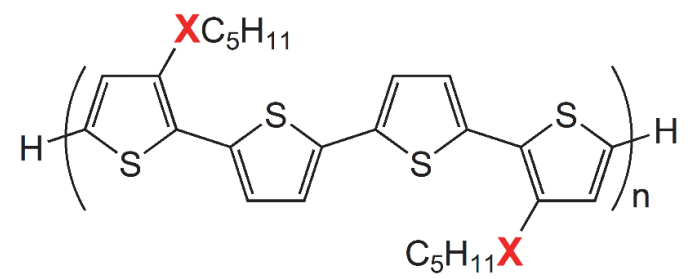

$X=$ O: DP4T $(n=1) ;$ TP8T $(n=2) ; \operatorname{HP12T}(n=3)$

$\mathrm{X}=\mathrm{CH}_{2}$ : DH4T $(\mathrm{n}=1)$; TH8T $(\mathrm{n}=2) ;$ HH12T $(\mathrm{n}=3)$

Fig. 1. Chemical structures of alkoxy- and alkylsubstituted oligothiophenes.

\section{Experimental}

2.1. Materials

$n$-Pentyl alcohol, $\quad n$-hexane, $\quad N, N$ dimethylformamide (DMF), dichloromethane, and tetrahydrofuran (THF) were purified using conventional methods and used immediately. Copper(I) bromide, palladium acetate $\left(\mathrm{Pd}(\mathrm{OAc})_{2}\right)$, tetra( $n$-butylammonium) bromide (TBAB), potassium acetate (KOAc), $n$-butyllithium (BuLi), and anhydrous copper(II) chloride were purchased from Tokyo Chemical Industries, Wako Pure Chemical, and Kanto Chemical and used without purification. Tetra(n-butylammonium) perchlorate (TBAP) and tetraethylammonium perchlorate (TEAP) were purified upon recrystallization from ethanol and dried in vacuo. 5,5'-Dibromo-2,2'bithiophene (DBr2T) was synthesized according to a literature procedure [35].

\subsection{Synthesis}

The synthetic routes used to prepare the three target oligothiophenes (DP4T, TP8T and HP12T) are shown in Scheme 1 and details of their synthetic procedures are described below.
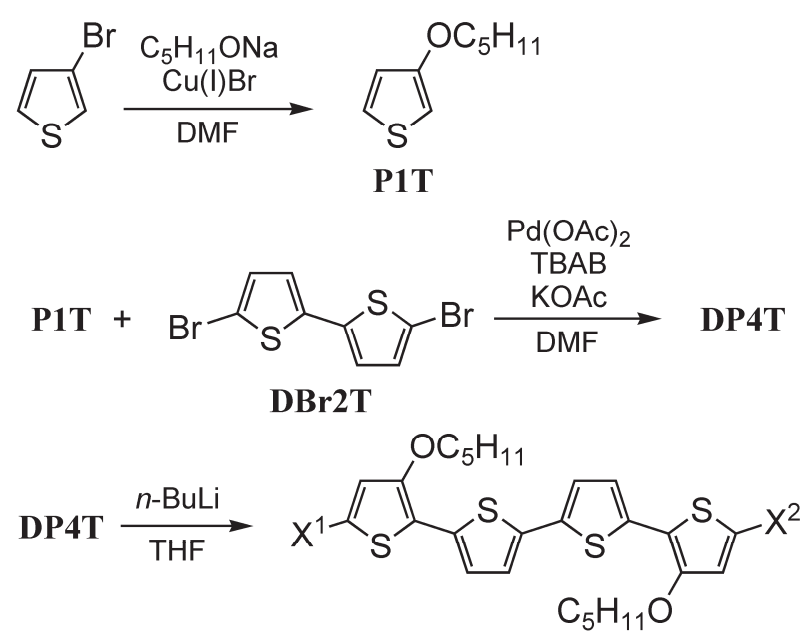

DP4T-1Li $\left(X^{1}=H, X^{2}=L i\right)$

DP4T-2Li $\left(X^{1}=X^{2}=L i\right)$

2 DP4T-1Li $\underset{\mathrm{THF}}{\stackrel{\mathrm{Cu}(\mathrm{II}) \mathrm{Cl}_{2}}{\longrightarrow}}$ TP8T

2 DP4T-1Li + DP4T-2Li $\underset{\mathrm{THF}}{\stackrel{\mathrm{Cu}(\mathrm{II}) \mathrm{Cl}_{2}}{\longrightarrow}}$ HP12T

Scheme 1. Synthetic routes used to prepare the target alkoxy-substituted oligothiophenes.

\subsubsection{3-(n-Pentyloxy)thiophene (P1T)}

P1T was synthesized according to a literature procedure [34]. Briefly, sodium $(3.7 \mathrm{~g}, 0.16 \mathrm{~mol})$ was added to $n$-pentyl alcohol (44 g, $0.5 \mathrm{~mol})$ and stirred at room temperature until the sodium disappeared completely. After the resultant suspension was concentrated in vacuo to remove the excess $n$-pentyl alcohol, a white powder was obtained. Under an inert atmosphere, DMF $(35 \mathrm{~mL})$ was added to the powder and 3-bromothiophene $(24.5 \mathrm{~g}, 0.15 \mathrm{~mol})$ was then added to the reaction mixture. After $5 \mathrm{~min}, \mathrm{Cu}(\mathrm{I}) \mathrm{Br}(1.4 \mathrm{~g}, 0.1 \mathrm{mmol})$ was added and the reaction mixture was stirred for $12 \mathrm{~h}$ at $90{ }^{\circ} \mathrm{C}$. After the reaction was allowed to cool to room temperature, the solution was poured into $n$ hexane. The solution was washed with saturated $\mathrm{NaHCO}_{3}$ solution and distilled water, then dried over anhydrous $\mathrm{Na}_{2} \mathrm{SO}_{4}$. After filtration, the solvent was removed in vacuo. The crude product was purified by column chromatography $\left[\mathrm{SiO}_{2}, n\right.$ hexane $\left./ \mathrm{CH}_{2} \mathrm{Cl}_{2}(8: 1, \mathrm{v} / \mathrm{v})\right]$ to afford P1T (15 g, 88 mmol, $88 \%$ ) as a pale-yellow liquid.

${ }^{1} \mathrm{H}$ NMR (500 MHz, $\left.\left(\mathrm{CD}_{3}\right)_{2} \mathrm{CO}, \delta, \mathrm{ppm}\right): 0.92$ (t, $\left.J=7.2 \mathrm{~Hz}, 3 \mathrm{H}, \quad \mathrm{CH}_{3}\right), 1.25-1.50(\mathrm{~m}, 4 \mathrm{H}$, $\left.\left(\mathrm{CH}_{2}\right)_{2} \mathrm{CH}_{3}\right), 1.75$ (tt, $\left.J=6.6 \mathrm{~Hz}, 2 \mathrm{H}, \mathrm{OCH}_{2} \mathrm{CH}_{2}\right)$, $3.96\left(\mathrm{t}, J=6.5 \mathrm{~Hz}, 2 \mathrm{H}, \mathrm{OC} \boldsymbol{H}_{2}\right), 6.43(\mathrm{dd}, J=1.5$, $3.1 \mathrm{~Hz}, 1 \mathrm{H}$, thienyl- $\boldsymbol{H}), 6.73(\mathrm{dd}, J=1.5,5.3 \mathrm{~Hz}, 1 \mathrm{H}$, thienyl- $\boldsymbol{H}), 7.29(\mathrm{dd}, J=3.1,5.3 \mathrm{~Hz}, 1 \mathrm{H}$, thienyl- $\boldsymbol{H})$. 


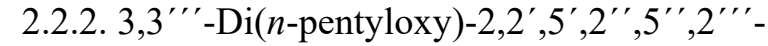
quaterthiophene (DP4T)

To a solution of DBr2T (1.0 g, $3.1 \mathrm{mmol})$ in DMF $(20 \mathrm{~mL})$ was added $\mathrm{Pd}(\mathrm{OAc})_{2}(40 \mathrm{mg}, 0.18 \mathrm{mmol})$, TBAB (2.8 g, $8.8 \mathrm{mmol}), \mathrm{KOAc}(2.6 \mathrm{~g}, 26 \mathrm{mmol})$, and P1 T (1.5 g, $8.8 \mathrm{mmol}$ ) at room temperature. The reaction mixture was stirred at $40{ }^{\circ} \mathrm{C}$ for $12 \mathrm{~h}$, cooled to room temperature, poured into distilled water $(30 \mathrm{~mL})$, and extracted with dichloromethane. The organic extract was washed with distilled water and dried over anhydrous $\mathrm{Na}_{2} \mathrm{SO}_{4}$. The solvent was removed in vacuo. DP4T (0.47 g, $0.94 \mathrm{mmol}, 30 \%)$ was obtained as a yellow powder after column chromatography $\left[\mathrm{SiO}_{2}, n\right.$-hexane/dichloromethane $(4 / 1, v / v)]$.

${ }^{1} \mathrm{H}$ NMR (500 MHz, $\left.\mathrm{CDCl}_{3}, \delta, \mathrm{ppm}\right): 0.96(\mathrm{t}, J=$ $\left.7.3 \mathrm{~Hz}, 6 \mathrm{H}, \mathrm{CH}_{3}\right), 1.42\left(\mathrm{tq}, J=7.4 \mathrm{~Hz}, 4 \mathrm{H}, \mathrm{CH}_{2} \mathrm{CH}_{3}\right)$, 1.53 (tt, $J=7.3 \mathrm{~Hz}, 4 \mathrm{H}, \mathrm{CH}_{2} \mathrm{CH}_{2} \mathrm{CH}_{3}$ ), 1.87 (tt, $J=$ $\left.6.5 \mathrm{~Hz}, 4 \mathrm{H}, \mathrm{OCH}_{2} \mathrm{CH}_{2}\right), 4.13(\mathrm{t}, J=6.5 \mathrm{~Hz}, 4 \mathrm{H}$, $\left.\mathrm{OCH}_{2}\right), 6.85(\mathrm{~d}, J=5.7 \mathrm{~Hz}, 2 \mathrm{H}$, thienylene- $\boldsymbol{H}), 7.06$ (d, $J=5.7 \mathrm{~Hz}, 2 \mathrm{H}$, thienylene- $\boldsymbol{H}), 7.06(\mathrm{~d}, J=3.7$ $\mathrm{Hz}, 2 \mathrm{H}$, thienyl- $\boldsymbol{H}), 7.12(\mathrm{~d}, J=3.7 \mathrm{~Hz}, 2 \mathrm{H}$, thienyl$\boldsymbol{H}$ ). HRMS (APCI) $\mathrm{m} / \mathrm{z}$ calcd for $\mathrm{C}_{26} \mathrm{H}_{30} \mathrm{O}_{2} \mathrm{~S}_{4}$ $502.11231\left(\mathrm{M}^{+}\right)$, found $502.11267\left(\mathrm{M}^{+}\right)$.

\subsubsection{Coupling reaction of DP4T}

To a solution of DP4T $(0.1 \mathrm{~g}, 0.2 \mathrm{mmol})$ in THF $(3 \mathrm{~mL})$ at $-30{ }^{\circ} \mathrm{C}$ was added $\mathrm{BuLi}(0.1 \mathrm{~mL}, 0.2$ mmol) via a syringe. The mixture was stirred at room temperature for $1 \mathrm{~h}$. Anhydrous $\mathrm{Cu}(\mathrm{II}) \mathrm{Cl}_{2}(32$ $\mathrm{mg}, 0.24 \mathrm{mmol}$ ) was added to the solution at $-78^{\circ} \mathrm{C}$ and the resulting mixture was allowed to warm up to room temperature for $6 \mathrm{~h}$. The solvent was then removed in vacuo and dichloromethane was added to the residue. The solution was washed with distilled water and dried over anhydrous $\mathrm{Na}_{2} \mathrm{SO}_{4}$. The solvent was removed in vacuo and the crude product was purified by a column chromatography $\left[\mathrm{SiO}_{2}, n\right.$-hexane/dichloromethane $\left.(4 / 1, \mathrm{v} / \mathrm{v})\right]$ to afford the dimer, TP8T ( $25 \mathrm{mg}, 25 \mu \mathrm{mol}, 25 \%)$ and trimer, HP12T (5.0 mg, $3.3 \mu \mathrm{mol}, 5 \%$ ) as dark-red solids in both cases.

${ }^{1} \mathrm{H}$ NMR data for TP8T $\left(500 \mathrm{MHz}, \mathrm{CDCl}_{3}, \delta\right.$, ppm): 0.96 (t, $\left.J=7.3 \mathrm{~Hz}, 6 \mathrm{H}, \mathrm{CH}_{3}\right), 0.97$ (t, $J=7.3$ $\left.\mathrm{Hz}, 6 \mathrm{H}, \mathrm{CH}_{3}\right), 1.40-1.48\left(\mathrm{~m}, 8 \mathrm{H}, \mathrm{CH}_{2} \mathrm{CH}_{3}\right), 1.50-$ $1.60\left(\mathrm{~m}, 8 \mathrm{H}, \mathrm{CH}_{2} \mathrm{CH}_{2} \mathrm{CH}_{3}\right), 1.82-1.96(\mathrm{~m}, 8 \mathrm{H}$, $\left.\mathrm{OCH}_{2} \mathrm{CH}_{2}\right), 4.04-4.23$ (m, 8H, OCH $\left.\boldsymbol{H}_{2}\right), 6.70-7.20$ (br, $14 \mathrm{H}$, thienyl- and thienylene- $\boldsymbol{H}$ ). HRMS data for TP8T (APCI) $\mathrm{m} / \mathrm{z}$ calcd for $\mathrm{C}_{52} \mathrm{H}_{58} \mathrm{O}_{4} \mathrm{~S}_{8}$ 1002.20953 $\left(\mathrm{M}^{+}\right)$, found 1002.21161 $\left(\mathrm{M}^{+}\right)$.

${ }^{1} \mathrm{H}$ NMR data for HP12T $\left(500 \mathrm{MHz}, \mathrm{CDCl}_{3}, \delta\right.$, ppm): 0.87-0.96 (m, 18H, CH $\left.\boldsymbol{H}_{3}\right), 1.32-1.43$ (m, 12H, $\left.\mathrm{CH}_{2} \mathrm{CH}_{3}\right), 1.43-1.53\left(\mathrm{~m}, 12 \mathrm{H}, \mathrm{CH}_{2} \mathrm{CH}_{2} \mathrm{CH}_{3}\right), 1.77-$ $1.90\left(\mathrm{~m}, 12 \mathrm{H}, \mathrm{OCH}_{2} \mathrm{CH}_{2}\right), 4.04-4.16(\mathrm{~m}, 12 \mathrm{H}$, $\left.\mathrm{OCH}_{2}\right), 6.75-7.13$ (br, 20H, thienyl- and thienylene$\boldsymbol{H}$ ). HRMS data for TP12T (APCI) $\mathrm{m} / \mathrm{z}$ calcd for $\mathrm{C}_{78} \mathrm{H}_{86} \mathrm{O}_{6} \mathrm{~S}_{12} 1502.30674\left(\mathrm{M}^{+}\right)$, found 1502.31010 $\left(\mathrm{M}^{+}\right)$.

\subsection{Characterization}

UV-vis absorption and fluorescence spectra were recorded on a Shimadzu UV-3150 spectrophotometer and a Hitachi F-4500 fluorescence spectrophotometer, respectively. Cyclic voltammetry and spectroelectrochemistry measurements were carried out in TEAP $(0.1 \mathrm{M})$ acetonitrile using a potentiostat/galvanostat (Hokuto Denko, HAB-151) and an X-Y recorder (Riken Denshi, F-57). In situ conductivity measurements were recorded in TEAP $(0.1 \mathrm{M})$ acetonitrile using a two-probe method with a microarray Pt electrode (ALS Co., Ltd, 65 lines, separation distance $=5 \mu \mathrm{m}$, total width $=260 \mu \mathrm{m})$ or a two-band Pt electrode (homemade, separation distance $=100 \mu \mathrm{m}$, width $=7 \mathrm{~mm}$ ). The amount of charge generated upon the electrochemical oxidation (doping) and reduction (dedoping) of the HP12T film was measured using a coulometer (homemade), where the potential was increased stepwise from $-0.4 \mathrm{~V}$ to the desired potential and then decreased back to $-0.4 \mathrm{~V}$, respectively. The doping levels, defined as the number of charges per thiophene ring, were estimated from the doping/dedoping charges, weight of HP12T film, and molecular weight of the monomer unit. The apparent mobility $(\mu)$ of the charge carriers in HP12T at various doping levels (electrode potentials) was calculated using the following relationship, $\mu=\sigma / n e$, where $\sigma, n$, and $e$ denote the electrical conductivity at an electrode potential, the density of charge carriers estimated from the doping/dedoping charges, and the elementary charge, respectively. The thickness of the HP12T film was evaluated using a 3D laser microscope (Keyence Corp., VK-9700).

\section{Results and discussion}

3.1. Synthesis of alkoxy-substituted oligothiophenes

Three oligothiophenes containing pendant alkoxy groups were synthesized according to the route shown in Scheme 1. 3-(n-Pentyloxy)thiophene (P1T), where one methylene group at the benzyl position of 3-hexylthiophene is replaced with an oxygen, was synthesized via a coupling reaction between 3-bromothiophene and sodium n- 
pentyloxide, which was freshly prepared upon the reaction of $n$-pentyl alcohol with sodium metal, in the presence of $\mathrm{Cu}(\mathrm{I}) \mathrm{Br} \quad[34,36] . \quad \mathrm{Di}(n-$ pentyloxy)quaterthiophene (DP4T) was synthesized via a direct $\mathrm{C}-\mathrm{H}$ arylation condensation reaction between 5,5'-dibromo-2,2'-bithiophene (DBr2T) and P1T using a catalytic system consisting of $\mathrm{Pd}(\mathrm{OAc})_{2}, \mathrm{KOAc}$, and $\mathrm{TBAB}$ in $\mathrm{DMF}$, according to a literature method $[37,38]$. In order to synthesize octamer (TP8T) and dodecamer (HP12T), the bromination of DP4T was examined, but the product was unstable even under dark and inert conditions and could not be isolated. Instead, DP4T was lithiated using BuLi and TP8T and HP12T were synthesized via a homocoupling reaction conducted in the presence of $\mathrm{Cu}(\mathrm{II}) \mathrm{Cl}_{2}$. Since the selectivity of the $\mathrm{H}$ atoms at $\alpha$-position of both terminal thiophene rings in DP4T are low, the lithiation of DP4T with BuLi proceeds at both positions to afford not only monolithiated DP4T (DP4T-1Li), but also dilithiated DP4T (DP4T-2Li). Thus, the coupling reaction of DP4T using BuLi gave not only TP8T via the homocoupling reaction of 2 equivalents of DP4T-1Li, but also HP12T via the cross-coupling reaction between 2 equivalents of DP4T-1Li and 1 equivalent of DP4T-2Li. Since the products contain several alkoxy groups including a long alkyl chain as a solubilizing group, they were soluble in common organic solvents and could be purified using conventional column chromatography as well as being clearly identified by ${ }^{1} \mathrm{H}$ NMR and mass spectroscopy.

\subsection{Optical properties}

The UV-vis absorption and emission spectra of DP4T, TP8T, and HP12T recorded in dichloromethane are shown in Fig. 2 and the optical properties are summarized in Table 1. It was found that the absorption and emission bands were redshifted upon increasing the number of thiophene units. The Stokes shift observed for DP4T was smaller than those of TP8T and HP12T. It has been already been reported that the rotational freedom around the single bond between two adjacent thiophene rings can be suppressed ("locked") due to the intramolecular interactions formed between chalcogen atoms, that is, the sulfur atoms in the thiophene ring and oxygen atoms in the alkoxy groups. The ratio of these "locked" single bonds decreases upon increasing the number of thiophene units, consequently DP4T, in which the rate of rotational freedom is relatively high, shows a smaller Stokes shift than TP8T or HP12T. As references, the optical properties of alkylsubstituted oligothiophenes (Fig. 1, $\mathrm{X}=\mathrm{CH}_{2}$, DH4T $(\mathrm{n}=1)$, TH8T $(\mathrm{n}=2)$, and HH12T $(\mathrm{n}=3))$ are listed in Table 1. By the replacing the benzylmethylene groups with oxygen atoms, the absorption bands were dramatically red-shifted. On the other hand, the emission spectra did not show such a significant red-shift.
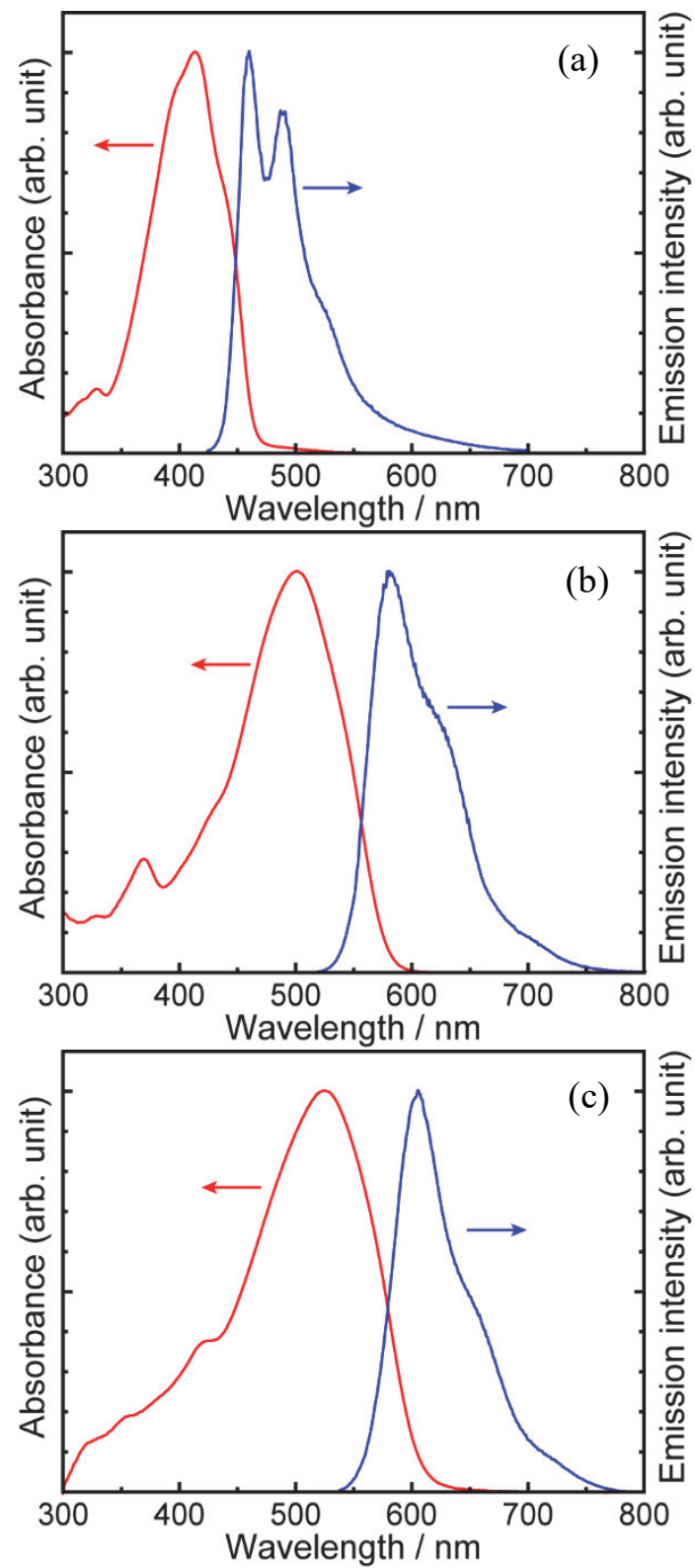

Fig. 2. Electronic absorption (red) and emission (blue) spectra of (a) DP4T, (b) TP8T and (c) HP12T in dichloromethane solution.

\subsection{Electrochemical properties}

$\mathrm{CV}$ measurements of the oligothiophenes were performed to investigate their electrochemical properties. The CV curves of their dichloromethane solutions are shown in Fig. 3. DP4T showed a pair 
Table 1. A summary of the optical properties of the as-prepared oligothiophenes.

\begin{tabular}{|c|c|c|c|c|c|}
\hline & \multicolumn{2}{|c|}{ Absorption } & \multirow{2}{*}{$\begin{array}{l}\text { Emission } \\
\lambda_{\max } / \mathrm{nm}\end{array}$} & \multirow{2}{*}{$\begin{array}{c}\text { Stokes shift } \\
\quad / \mathrm{nm}\end{array}$} & \multirow[t]{2}{*}{ Ref. } \\
\hline & $\lambda_{\max } / \mathrm{nm}$ & $\begin{array}{c}\varepsilon 10^{4} \\
/ \mathrm{M}^{-1} \mathrm{~cm}^{-1}\end{array}$ & & & \\
\hline DP4T & 412 & 3.2 & 459 & 47 & This work \\
\hline TP8T & 500 & 5.7 & 580 & 80 & This work \\
\hline HP12T & 525 & 9.8 & 673 & 148 & This work \\
\hline DH4T & 377 & 2.9 & 455 & 78 & [40] \\
\hline TH8T & 439 & 6.5 & 543 & 104 & [40] \\
\hline HH12T & 457 & 9.0 & 561 & 110 & [40] \\
\hline
\end{tabular}

of reversible redox peaks at $0.23 \mathrm{~V}$ vs. $\mathrm{Fc} / \mathrm{Fc}^{+}$, which were attributed to the first oxidation process. The first oxidation potential of DH4T was reported to be $1.13 \mathrm{~V}$ vs. $\mathrm{Fc} / \mathrm{Fc}^{+}$[41], which is much more positive than that of DP4T. Furthermore, in the case of alkyl-substituted quaterthiophenes like DH4T, the first redox process is irreversible due to the instability of the radical-cation species generated during the oxidation reaction [42], so that the polymeric material is deposited on the working electrode via the electrolytic polymerization of DH4T. Thus, when the redox cycle was repeated, the current intensity of $\mathrm{CV}$ curve was gradually increased due to the deposition of the electrochemical active material. On the other hand, the introduction of an electron-donating alkoxy group stabilizes the radical-cation species of DP4T, which results in a reversible $\mathrm{CV}$ curve and shifts the oxidation potential to the negative region. TP8T also showed a pair of reversible redox waves at $0.03 \mathrm{~V}$ vs. $\mathrm{Fc} / \mathrm{Fc}^{+}$, but when the sweep range was further expanded to the positive region, another pair of reversible redox waves was observed. This was attributed to not only the radical-cation species, but also the dication species of TP8T becoming more stable upon the expansion of the $\pi$-conjugated system. HP12T shows two pairs of reversible redox waves that almost overlap at $-0.14 \mathrm{~V}$ vs $\mathrm{Fc} / \mathrm{Fc}^{+}$. This result is similar to the $\mathrm{CV}$ curve obtained for dodecathiophene, previously reported by Noma et al [43]. In their report, they explained using coulometry that this oxidation process is a one-step, two-electron oxidation process. This result was attributed to the difference between the first and second oxidation processes being diminished due to the decreased Coulombic repulsion upon increasing the number of thiophene units.

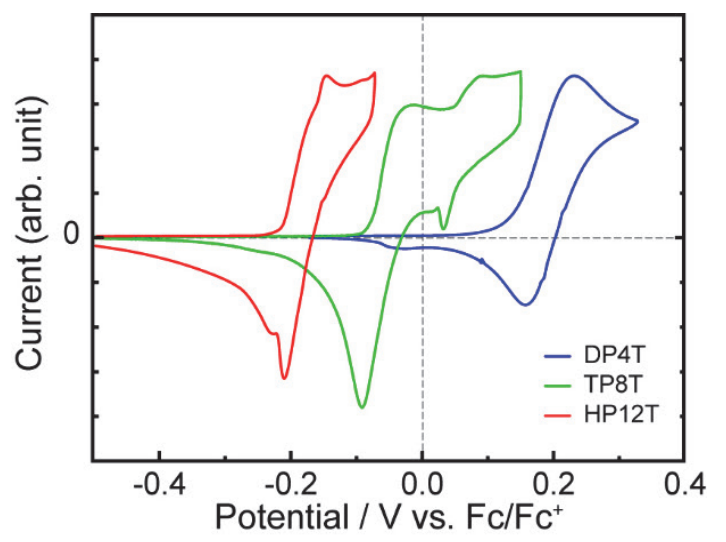

Fig. 3. Cyclic voltammograms obtained for DP4T (blue), TP8T (green), and HP12T (red) in dichloromethane. Scanning rate: $10 \mathrm{mV} \mathrm{s}^{-1}$, electrolyte: $\operatorname{TBAP}(0.1 \mathrm{M})$.

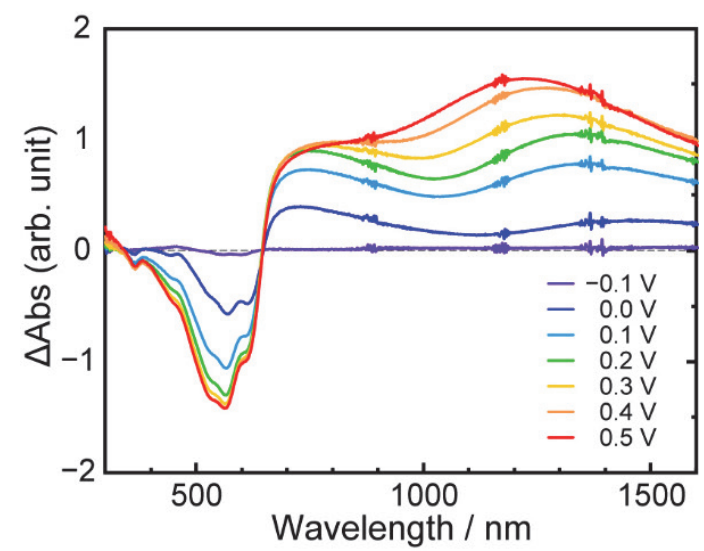

Fig. 4. Spectroelectrochemistry of HP12T.

In order to understand the oxidation process of HP12T in more detail, spectroelectrochemistry was performed using an ITO substrate coated with HP12T, platinum wire, and $\mathrm{Ag} / \mathrm{Ag}^{+}$as the working, counter, and reference electrodes, respectively (Fig. 4). The absorption spectrum of neutral HP12T 
recorded in the film state showed an absorption maximum at $570 \mathrm{~nm}$, corresponding to the $\pi-\pi^{*}$ transition, which was red-shifted by $\sim 50 \mathrm{~nm}$ when compared to that observed in the solution state, and showed a well-resolved vibronic structure due to the existence of rotational isomers. When HP12T was oxidized at $0.0 \mathrm{~V}$ vs. $\mathrm{Ag} / \mathrm{Ag}^{+}$, the intensity of the absorption band observed at $570 \mathrm{~nm}$ decreased and two new peaks were observed at $\sim 750$ and $\sim 1400$ $\mathrm{nm}$. The intensity of these peaks increased upon increasing the electrode potential. When the HP12T was oxidized at more positive potentials than $0.2 \mathrm{~V}$, the intensity of these peaks became saturated and one broad peak was observed at $\sim 1200 \mathrm{~nm}$. These changes were similar to our previous results observed for polythiophenes [44-46] and oligothiophenes $[28,47,48]$, and the former and latter peaks can be ascribed to the one-electron oxidized species (radical-cation or $\pi$-dimer) and the two-electron oxidized species (dication) of HP12T, respectively. These results suggest that HP12T shows a one-step, two-electron oxidation process within this electrode potential range.

\subsection{Electrical properties}

Since HP12T has excellent film-forming properties using the spin-coating technique, the electrical properties of the HP12T film can be investigated. In general, the electrical conductivity of $\pi$-conjugated materials is strongly affected by their doping levels. Therefore, in order to evaluate the electrical properties of HP12T in detail, it is necessary to control its doping levels. We have established an in-situ measurement system to investigate the electrical conductivity in each doped state by controlling the doping levels of polythiophene and oligothiophene using an electrochemical method [28,44-48]. Using this technique, the electrical properties of HP12T were investigated (Fig. 5). As the electrode potential was positively shifted from $-0.4 \mathrm{~V}$ to $0.1 \mathrm{~V}$, the doping levels of HP12T increased linearly from 0.06 to $14 \%$. When the electrode potential was shifted more positively, the doping levels gradually saturated, and finally reached a doping level of $\sim 35 \%$ at $0.5 \mathrm{~V}$. This value means that one dication is delocalized among seven thiophene units. At the same time as the doping levels increased, the electrical conductivity also increased from $9.1 \times 10^{-9}$ to $1.0 \times$ $10^{0} \mathrm{~S} \mathrm{~cm}^{-1}$.

To gain more insight into the charge-transport properties of TP12T film, the apparent chargecarrier mobility was estimated by combining the

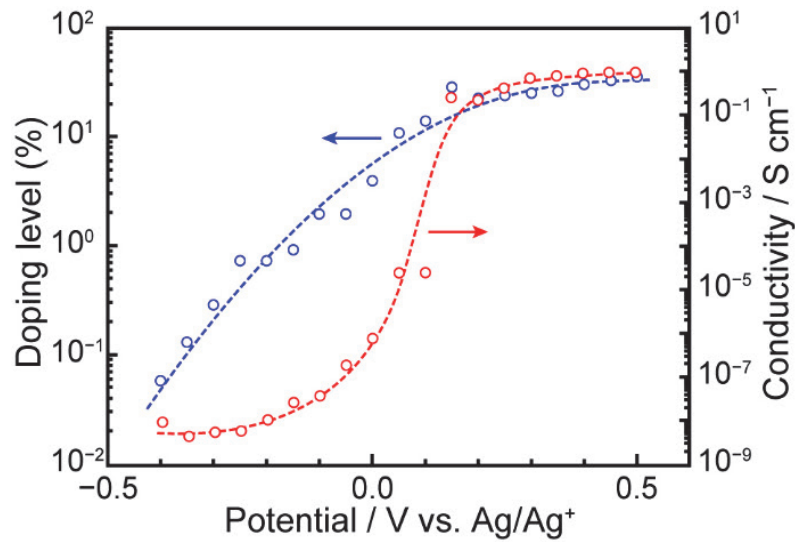

Fig. 5. Doping level and electrical conductivity of HP12T film plotted against the electrode potential.

data obtained for the doping levels and electrical conductivity (Fig. 6). At doping levels ranging from 0.06 to $0.7 \%$, the mobility decreased slightly upon increasing the doping level. Upon increasing the doping level from 0.7 to $25 \%$, the mobility increased by almost six orders of magnitude from 1 $\times 10^{-9}$ to $4 \times 10^{-3} \mathrm{~cm}^{2} \mathrm{~V}^{-1} \mathrm{~s}^{-1}$. When the doping level was increased beyond $25 \%$, the mobility was almost saturated and finally decreased only slightly. The behavior of these changes was almost the same as that observed for other polythiophenes and oligothiophenes reported to date. These reports explain this behavior as follows: At a low doping level of $<1 \%$, the charge-carriers (mainly, radical cations) will move by hopping between adjacent molecules (hopping transport mechanism). However, the hopping-site distance of the carriers will be expanded upon swelling of the cast film induced by the incorporation of anions surrounded by solvent molecules into the film, and thus the mobility is reduced. Then, the charge-transport mechanism was changed from hopping conduction to metallic conduction upon changing the predominant carrier species from the radical cations to dications, so that the mobility was drastically enhanced. At a higher doping level, almost all of the HP12T molecules are two-electron oxidized and thus it becomes difficult for the hole carriers to move among the molecules because of the Coulombic repulsion and saturated mobility. The electrical conductivity of the electrochemicallydoped HP12T is the highest value among the oligothiophenes investigated using in-situ conductivity measurement to date and this result implies that the introduction of alkoxy groups improves not only their solubility in common organic solvents, but also the electrical conductivity of oligothiophenes. 


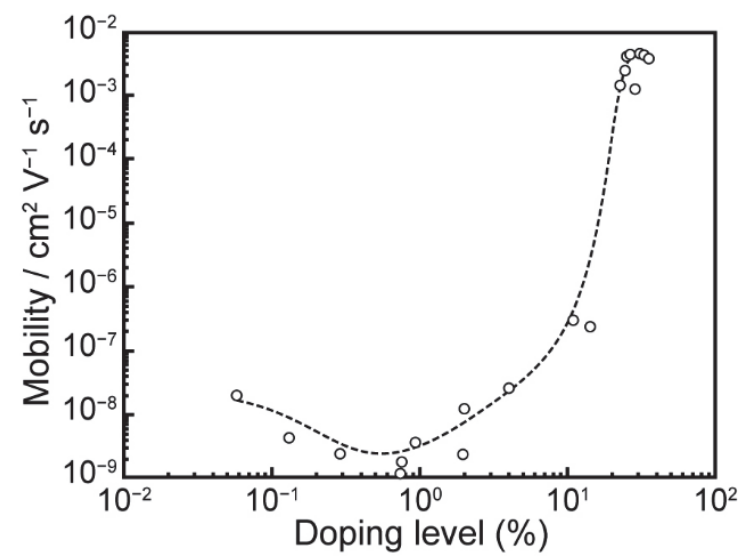

Fig. 6. Apparent mobility of the charge carries in HP12T film plotted against the doping level.

\section{Conclusion}

Three oligothiophenes containing electrondonating alkoxy substituents as side chains have been synthesized. These oligothiophenes show high solubility in common organic solvents due to the alkyl chains introduced in the alkoxy groups. The introduction of electron-donating alkoxy groups induced a negative shift in the oxidation potential and reduced the steric hindrance causing a red-shift in the absorption band upon extending the length of the $\pi$-conjugation system. As the number of thiophene units increased, the oxidation potentials shifted to the negative region and the oxidized species were stabilized due to the reduction in the Coulombic repulsion. The stabilization of the oxidized species affected the charge-transport properties and electrochemically-doped dodecathiophene showed excellent conductivity. These results will give useful information for the development of organic electric materials.

\section{Acknowledgements}

This work was partially supported by grants from the Nakanishi Scholarship Foundation and Murata Science Foundation (I. I.). The authors are grateful to Drs. Tomoko Amimoto and Daisuke Kajiya, the Natural Science Center for Basic Research and Development (N-BARD), Hiroshima University for mass spectroscopy measurements.

\section{References}

1. T. A. Skotheim and J. R. Reynolds, "Handbook of Conducting Polymers", 3rd Edition, CRC Press, Boca Raton (2007).

2. S.-S. Sun and L. R. Dalton, "Introduction to Organic Electronic and Optoelectronic Materials and Devices", CRC Press, Boca Raton (2008).

3. M. Leclerc and J. F. Morin, "Design and
Synthesis of Conjugated Polymers", WileyVCH, Weinheim (2010).

4. Y. Chujo, "Conjugated Polymer Synthesis: Methods and Reactions", Wiley-VCH, Weinheim (2010).

5. G. Inzelt, "Conducting Polymers: A New Era in Electrochemistry", Springer, Heidelberg (2012).

6. S. Huang, Y. Liu, Y. Zhao, Z. Ren, and C. F. Guo, Adv. Funct. Mater, 29 (2019) 1805924.

7. N. Toshima, Synth. Metals, 225 (2017) 3.

8. S. Kirchmeyer and K. Reuter, J. Mater. Chem., 15, (2005) 2077.

9. A. Elschner, S. Kirchmeyer, W. Lövenich, U. Merker, and K. Reuter, "PEDOT: Principles and Applications of an Intrinsically Conductive Polymer", CRC Press, Boca Raton (2011).

10. I. Imae, Y. Nakamura, K. Komaguchi, Y. Ooyama, J. Ohshita, and Y. Harima, Sci. Tech. Adv. Mater., 13 (2012) 045005.

11. M. Vosgueritchian, D. L. Lipomi, and Z. Bao, Adv. Funct. Mater, 22 (2012) 421.

12. O. Bubnova, Z. U. Khan, A. Malti, S. Braun, M. Fahlman, M. Berggren, and X. Crispin, Nat. Mater., 10 (2011) 429.

13. G.-H. Kim, L. Shao, K. Zhang, and K. P. Pipe, Nat. Mater., 12 (2013) 12, 719.

14. Q. Wei, M. Mukaida, K. Kirihara, Y. Naitoh, and T. Ishida, Materials, 8 (2015) 732.

15. P. Bäuerle, Adv. Mater., 4 (1992) 102.

16. P. Bäuerle, "Oligothiophenes", K. Müllen and G. Wegner, Eds., "Electronic materials: the oligomer approach", Weinheim: Wiley-VCH (1998) 105.

17. R. D. McCullough, Adv. Mater., 10 (1998) 93.

18. J. Roncali, J. Mater. Chem., 9 (1999) 1875.

19. D. Fichou, J. Mater. Chem., 10 (2000) 571.

20. D. Fichou, "Handbook of oligo- and polythiophenes", Weinheim: Wiley-VCH (1999).

21. I. F. Perepichka and D. F. Perepicjka, Eds, "Handbook of thiophene-based materials: applications in organic electronics and photonics", Chichester: John Wiley \& Sons Ltd (2009).

22. J. L. Segura and N. Martín, J. Mater. Chem., 10 (2000) 2403.

23.T. Otsubo, Y. Aso, and K. Takimiya, J. Mater. Chem., 12 (2002) 2565.

24. A. R. Murphy and J. M. J. Fréchet, Chem. Rev., 107 (2007) 1066.

25. A. Mishra, C.-Q. Ma, and P. Bäuerle, Chem. Rev., 109 (2009) 1141.

26. J. L. Segura, H. Herrera, and P. Bäuerle, J. Mater. 
Chem., 22 (2012) 8717.

27. A. L. Kanibolotsky, N. J. Findlay, and P. J. Skabara, Beilstein J. Org. Chem., 11 (2015) 1749.

28. I. Imae, S. Imabayashi, K. Komaguchi, Z. Tan, Y. Ooyama, and Y. Harima, RSC Adv., 4 (2014) 2501.

29. I. Imae, H. Sagawa, T. Mashima, K. Komaguchi, Y. Ooyama, and Y. Harima, Open J. Polym. Chem., 4 (2014) 83.

30. I. Imae, K. Korai, Y. Ooyama, K. Komaguchi, and Y. Harima, Synth. Met., 207 (2015) 65.

31. I. Imae, T. Koshima, K. Korai, Y. Ooyama, K. Komaguchi, and Y. Harima, Dyes Pigm., 132 (2016) 262.

32. I. Imae, Y. Ito, S. Matsuura, and Y. Harima, Org. Electron., 37 (2016) 465.

33. I. Imae, H. Sagawa, and Y. Harima, Jpn. J. Appl. Phys., 57 (2018) 03EJ01.

34. I. Imae, N. Tada, and Y. Harima, J. Photopolym. Sci. Tech., 32 (2019) 585.

35. I. Imae, K. Nawa, Y. Ohsedo, N. Noma, and Y. Shirota, Macromolecules, 30 (1997) 380.

36. M. A. Keegstra, T. H. A. Peters, and L. Brandsma, Tetrahedron, 48 (1992) 3633.

37. A. Borghese, G. Geldhof, and L. Antoine, Tetrahedron Lett., 47 (2006) 9249.

38. I. Imae, M. Kumano, and Y. Harima, Sci. $A d v$. Mater., 11 (2019) 792.
39. J.-M. Raimundo, P. Blanchard, P. Frère, N. Mercier, I. Ledoux-Rak, R. Hierle, and J. Roncali, Tetrahedron Lett., 42 (2001) 1507.

40. T. Yamamoto, Y. Aso, T. Otsubo, H. Tang, Y. Harima, and K. Yamashita, Chem. Lett., 28 (1999) 443.

41. A. Facchetti, M.-H. Yoon, C. L. Stern, G. R. Hutchison, M. A. Ratner, and T. J. Marks, J. Am. Chem. Soc., 126 (2004) 13480.

42. I. Imae, K. Moriwaki, K. Nawa, N. Noma, and Y. Shirota, Synth. Met., 69 (1995) 285.

43. S. Funaoka, I. Imae, N. Noma, and Y. Shirota, Synth. Met., 101 (1999) 600.

44. I. Imae, S. Imabayashi, K. Korai, T. Mashima, Y. Ooyama, K. Komaguchi, and Y. Harima, Mater. Chem. Phys., 131 (2012) 752.

45. I. Imae, T. Mashima, H. Sagawa, K. Komaguchi, Y. Ooyama, and Y. Harima, J. Solid State Electrochem., 19 (2015) 71.

46. I. Imae, R. Ogino, Y. Tsuboi, T. Goto, K. Komaguchi, and Y. Harima, RSC Adv., 5 (2015) 84694.

47. I. Imae, D. Tokita, Y. Ooyama, K. Komaguchi, J. Ohshita, and Y. Harima, Polym. Chem., 2 (2011) 868 .

48. I. Imae, D. Tokita, Y. Ooyama, K. Komaguchi, J. Ohshita, and Y. Harima, J. Mater. Chem., 22 (2012) 16407. 